\title{
A EXPLORAÇÃO DO TRABALHADOR ENTREGADOR MEDIADO POR APLICATIVO COMO UMA EXPRESSÃO DO CAPITALISMO GLOBAL E COLONIZADOR: ALGUMAS CONSIDERAÇÕES INICIAIS
}

\section{Nicolle W. da Silva Gonçalves ${ }^{1}$}

RESUMO: Em uma análise da condição de exploração do trabalhador por aplicativo, o presente trabalho tem o objetivo de traçar algumas reflexões iniciais acerca de dois elementos que conectam o capitalismo global, materializado nas empresas transnacionais, ao período de colonização das Américas: a expropriação de direitos do outro e o discurso de individualismo meritocrático. Para tanto, tendo por ponto de partida os conceitos de "Sistema-mundo" e "Modernidade", serão caracterizados o capitalismo e a globalização como uma continuidade reformulada daquilo que foi estabelecido no período colonial, com reflexos diretos na atual Divisão Internacional do Trabalho. A hipótese é que a exploração colonial aos países periféricos permanece através da atuação das empresas transnacionais que se aproveitam da vasta mão-de-obra disponível para extrair lucro e direcionar a massa trabalhadora em sentido ao cumprimento dos seus objetivos. O caso dos entregadores será utilizado como referencial para análise da expressão prática do capitalismo neoliberal no Sul-Global: encontram-se invisibilizados em seus direitos, ao mesmo tempo que estão inseridos em uma dinâmica de aparente autonomia, responsáveis pelo seu sucesso e fracasso. De outro lado, as empresas de aplicativo se colocam na retaguarda de uma narrativa de neutralidade da tecnologia e da globalização homogeneizadora. Sem pretensões de esgotamento do tema, o ponto principal é refletir como a permanente expropriação de direitos do outro e o discurso de individualismo meritocrático, que acompanham a dialética do centro e da periferia global, são características fundantes da criação do próprio capitalismo, germinado da relação entre colonizador e colonizado.

PALAVRAS-CHAVE: Trabalhador mediado por aplicativo. Capitalismo global. Colonialidade. Economia de compartilhamento. Precarização do trabalho.

1 Graduada em Direito pela Universidade de Brasília. Especialista em Direito do Trabalho e Processo de Trabalho pelo Instituto Brasiliense de Direito Público. Mestranda em Direito na Universidade Federal de Ouro Preto. Integrante do Grupo de Estudos de Direito do Trabalho (GEDIT) da UFOP. E-mail de contato: nicollewdsg@gmail.com. 


\section{INTRODUÇÃO}

O objetivo do trabalho é fazer uma reflexão inicial sobre dois dos elementos que conectam o capitalismo global ao período colonial, no sentido de que permaneceram ao longo da história, mas transmutaram-se para se adequar às novas necessidades do padrão de poder capitalista: a expropriação de direitos do outro e o discurso de individualismo meritocrático que coloca a responsabilidade do próprio sucesso sobre aquele que é estruturalmente excluído. A hipótese é que a exploração colonial aos países periféricos permanece ${ }^{2}$ através da atuação das empresas transnacionais que se aproveitam da vasta mão-de-obra disponível para extrair lucro e direcionar a massa trabalhadora em sentido ao cumprimento dos seus objetivos. Essa movimentação está inserida em uma política neoliberal e é aprofundada pela inserção da tecnologia nas relações de trabalho, que distanciam os trabalhadores dos centros de comando, e ocultando o vínculo de emprego e a condição de assalariamento. Assim, por meio de uma elaboração entre a categoria de "Sistema-mundo" de Wallerstein, (2007) e o que Dussel (1994) entende por "Modernidade" pretende-se ponderar acerca de alguns pontos que fundamentam o capitalismo atual e que possui vários aspectos em comum com o período colonial, em termos de relação centro-periferia.

Para tanto, parte-se do pressuposto de que o capitalismo é resultado de um antigo relacionamento entre os países centrais e periféricos, que teve como ponto de partida o reconhecimento do europeu enquanto um ser moderno e, portanto, superior. Nesse enredo, a globalização é a narrativa que oculta as desigualdades e, em especial, o papel de protagonismo que as pessoas, as plantas, o solo, os animais e as riquezas minerais das Colônias tiveram em todo o processo de "sucesso histórico" dos países centrais. Reconhece-se assim, que há uma "dialética tripla" (CORONIL, 2005, p. 3) entre trabalho, o capital e a terra, que dá à história do capitalismo um aspecto global desde o seu início. Isso é importante porque um dos pontos centrais da narrativa eurocêntrica é a perspectiva de que a sua modernidade foi fruto de seu próprio mérito (a centralidade está no homem burguês moderno) e não de uma relação de subalternização e expropriação do outro, que repercute na atual Divisão Internacional do Trabalho (CORONIL, 2005).

Por fim, a atuação das empresas transnacionais será pensada a partir da realidade dos entregadores por aplicativo, com ênfase nos países LatinoAmericanos, que tem a sua mão-de-obra gerenciada por grandes corporações com sede localizada em países de capitalismo central. O destaque será para duas principais características dessa relação de trabalho: negação de direitos aos trabalhadores, vistos por meio do algoritmo, e um discurso de neutralidade e promoção de autonomia aos dos mesmos. A análise da atuação das empresas passa pelo ideal de "Economia de Compartilhamento", como parte da propaganda feita pelo capitalismo, mas que é distante da realidade a qual são submetidos estes

2 Existem outras manifestações da permanência de uma relação colonial, contudo, não serão objetos do presente artigo. 
trabalhadores. É importante dizer que embora se reconheça que a precarização do trabalho acontece de modo universal, já que esta é a lógica do sistema capitalista, não se pode negar as consequências históricas dos padrões de exploração ao Sul Global para a classe trabalhadora, e a existência de condições que impedem o rompimento desta relação de subalternidade.

A metodologia utilizada será a de revisitação bibliográfica, somada à coleta de material de fontes primárias e secundárias que contextualizam as condições as quais são submetidos os entregadores mediados por aplicativo, ao prestarem serviços para as empresas transnacionais. Sem pretensões de esgotamento do tema, o ponto principal é refletir como a permanente expropriação de direitos do outro e o discurso de individualismo meritocrático, que acompanham a dialética do centro e da periferia global, são características fundantes da criação do próprio capitalismo, germinado da relação entre colonizador e colonizado.

\section{O SISTEMA-MUNDO E A COLONIZAÇÃO DAS AMÉRICAS}

O conceito de "Sistema-mundo" (WALLERSTEIN, 2007, p. 27) de Wallerstein é um bom ponto de partida para a análise que se pretende fazer neste trabalho. Para o autor, o Sistema-Mundo é a forma de organização ocidental e capitalista que formata o saber, o ser e o produzir do mundo em que vivemos. É um sistema que exporta uma "Modernidade" vinda da Europa, com pretensão de valores universais e controle da narrativa da história da humanidade. Esse sistema encontrou solo fértil a partir da colonização das Américas: um primeiro contato entre a Europa e o "resto do mundo" com características que são muito decisivas para o que nós somos agora, para o que a Europa é agora (e o sentido de Europa pode ser expandido para o que, hoje, entende-se como "países desenvolvidos") e para a forma como o capitalismo entrelaça os países centrais e os países periféricos.

Quando a Europa se expandiu para além do seu continente (depois de já ter estabelecido um vínculo de superioridade e dominação com a África e com a Ásia) relacionou-se com a natureza e com os habitantes deste novo território com encobrimento, violência, domínio político, militar e físico. Não houve encontro de culturas, já que uma (europeia) se impôs sobre todas as outras:

El concepto de "encuentro" es encubridor porque se establece ocultando la dominación del "yo" europeo, de su "mundo", sobre el "mundo del Otro", del indio. No podía entonces ser un "encuentro" entre dos culturas - una "comunidad argumentativa" donde se respetara a los miembros como personas iguales-, sino que era una relación asimétrica, donde el "mundo del Otro" es excluido de toda racionalidad y validez religiosa posible. En efecto, dicha exclusión se justifica por una argumentación 
encubiertamente teológica: se trata de la superioridad - reconocida o inconsciente - de la "Cristiandad" sobre las religiones indígenas (DUSSEL, 1994, p. 62).

Uma data importante para Enrique Dussel é 1492, o ano em que Colombo chegou às Américas para marcar o que seria um longo processo de encobrimento do que não era europeu e despontamento da "Modernidade". Não houve um reconhecimento do outro como um ser diferente e ao mesmo tempo igual3. $\mathrm{O}$ conquistador, frente ao nativo que via como uma sub-categoria de humano, impôs a sua individualidade sem o reconhecer como um sujeito portador de sua própria cultura, subjetividade e modo de conhecer e reconhecer o mundo. É uma relação antagônica, de projeção do mundo europeu e de submissão pedagógica, cultural, política, econômica e sexual, que deu a tonalidade de como seria a relação da Europa com as Américas a partir de então (DUSSEL, 1994).

Em uma perspectiva de negação absoluta de direitos, ao não reconhecer o outro como sujeito, a Europa enlaçou a América como sua periferia, o que resultou em uma polarização determinante para a constituição da Modernidade e do homem moderno. O encobrimento do "mundo do outro" (DUSSEL, 1994, p. 62) se deu a partir de uma racionalidade construída tendo por base o argumento de superioridade do mundo ocidental em relação às outras culturas, porque é a única que se basearia em valores e verdades universais (WALLERSTEIN, 2007). Por conseguinte, ao anular o outro enquanto sujeito, o europeu teria como justificativa uma missão emancipadora da irracionalidade e do atraso, em que a única solução seria empurrar todos os não-europeus para uma razão de mundo que se pretende universal e que tem a Europa como referência do que é ser racional e moderno (DUSSEL, 1994). A configuração do SistemaMundo Moderno, portanto, se constituiu a partir do enlace entre colonizador e colonizado, onde este último fornece o enriquecimento material e de autoestima necessários ao homem europeu em troca de ocultamento e exploração. Tal autoestima se formou a partir do seu reconhecimento enquanto centro de uma "periferia" que se constituía ao seu redor, entendendo-a como subalterna, imatura e bárbara. A partir deste ponto, traça-se uma linha divisória, entre aqueles que são desenvolvidos e os que não são desenvolvidos, de onde se desenrola toda a história da humanidade (MORENO, 2005).

A história ocidental é contada do ponto de vista dos vencedores, dos modernos e desenvolvidos europeus que saíram para explorar o restante do mundo sob a justificativa de espalhar civilidade e modernização. Nesse sentido, sobre o ocultamento de várias outras narrativas, a Europa se coloca como ponto de começo e de final, como um destino desejado para a toda a humanidade, ou seja, em uma perspectiva desenvolvimentista, tudo o que não é Europa quer traçar o

3 Reconhecimento do outro como igual no sentido de ser sujeito de direitos, e como diferente no sentido de possuir sua própria visão de mundo, história, costumes e assim por diante. 
mesmo caminho em busca do que foi construído por ela. E o que foi construído? As instituições modernas, em especial, o capitalismo (MAGALHÃES, 2012).

\title{
3. O CAPITALISMO E A GLOBALIZAÇÃO COMO MARCAS DE UMA COLONIALIDADE
}

A colonização da América teve especial importância na definição do capitalismo que está desenhado hoje. A exploração da natureza e dos nativos implicou em acúmulo de riqueza para a Europa, decorrente de um encontro que possuiu duas vias de mão única: de um lado o florescimento de um sistema centrado na propriedade privada e, do outro lado, a expropriação das riquezas naturais, o trabalho barato e uma condenação à permanência na periferia da história. As condições para o desenvolvimento do capitalismo na Europa só foram possíveis diante do trabalho "não-livre" das colônias. A lógica de acumulação de riqueza teve como sua forma incipiente a "acumulação primitiva" colonial, inclusive sob o ponto de vista de possibilitar o surgimento do modo de produzir das fábricas e o trabalho assalariado, no começo da industrialização europeia (CORONIL, 2005):

\begin{abstract}
Assim como as plantações das Américas, operadas por escravos africanos, funcionaram como fábricas proto-industriais que precederam aquelas estabelecidas em Manchester ou em Liverpool com mãode-obra europeia assalariada (Mintz, 1985), as colônias americanas prefiguraram as estabelecidas na África e Ásia durante a era do alto imperialismo (CORONIL, 2005, p. 4).
\end{abstract}

O sistema capitalista se sustenta no indivíduo autônomo, que surge com o aparecimento do primeiro burguês (mas com muito do ego do colonizador), responsável por si mesmo e pelos bens que é proprietário, que se relaciona com outros indivíduos proprietários em ações fragmentárias, individuais e que geram o mercado como sistema. Esse indivíduo autônomo se instala como prática social histórica, a partir da qual todas as instituições modernas são dispostas, inclusive em termos do que é prioridade ou não na formulação do direito moderno (MORENO, 2005). E é a partir da centralidade do indivíduo moderno que é contada a história da humanidade. Deixa de existir uma pluralidade de narrativas, e a narrativa dominante passa a ser do sucesso da racionalidade europeia, como um padrão de humanidade. O Sistema-Mundo Moderno não permite a existência de outras formas de existir no mundo e não admite o fato de alguém não querer estar incluso. É uma lógica que parece mais desenvolvida e deve ser irrecusável. Porque os não-europeus não iriam querer essa vida? 
Garci Diez, o pai dominicano que relata a visita à região de Lupaca, relata com indignação o fato de que as mulheres irão produzir tejidos, costurando a pedido de Mallku (a autoridade suprema da região), sem receber, aos seus olhos, nada mais do que um pouco de comida e outros pequenos reconhecimentos. Garci Diez acredita que as mulheres devam receber um salário pelo seu trabalho e é isso que os espanhóis vão lhes dar, ao invés de apenas comida e outros pequenos reconhecimentos variados. Mas, ó infelicidade, as mulheres se recusaram a lidar com os espanhóis, não estão interessadas em salário, e somente farão o trabalho para e quando Malku as pedir para fazê-lo (MIGNOLO, 2008, p. 307).

A narrativa se centra em apontar para o Ocidente como a melhor expressão evolutiva da humanidade e como única "linha de chegada" possível e desejável para todo o restante (MORENO, 2005). A maneira mais evoluída de existir, portanto, seria a da sociedade do indivíduo autônomo, da propriedade privada e do capitalismo ocidental. É importante dizer que essa história única omite o protagonismo das colônias (subjugadas) no sucesso do empreendedorismo capitalista e, na realidade, ela aposta em dois principais argumentos autocentrados: o indivíduo autônomo que triunfa sobre o seu próprio esforço em um sistema imparcial (sistema que existe por si só) e que o capitalismo é um projeto universal sem possibilidade de ser mudado (MORENO, 2005). E é nesse enredo em que se mantém o triunfo do capitalismo ao longo da história da humanidade, diferenciando os seus incluídos dos seus excluídos, em permanente dominação dos países centrais sobre os países periféricos e na constante expropriação de riqueza. O que mudou ao longo dos anos foi apenas o modo da exclusão, conforme veremos mais adiante.

A colonização política e militar deixou de existir com as proclamações de independência dos países Latino-Americanos, mas a colonialidade ${ }^{4}$ permaneceu por meio da absorção de tudo aquilo que é proveniente do Ocidente, em especial, o sistema capitalista e toda a sua narrativa de vitoriosos e derrotados. Nesse sentido, a dualidade de ganho para uns e precariedade para outros permanece mesmo com o amadurecimento e propagação do capitalismo industrial para além da Europa. Dussel (1994) entende que "os trabalhadores" (DUSSEL, 1994, p. 163) é uma das outras faces da Modernidade colonizadora que expandiu o sistema capitalista para as ex-colônias sob a forma de um capitalismo periférico e dependente, que transfere estruturalmente valor para o capital central ao fornecer um ambiente fértil de mão-de-obra barata e sobre-explorada, acompanhada de uma multidão ociosa que estica os patamares trabalhistas ainda mais para baixo. Esse aspecto é crucial para a análise que se pretende fazer no presente artigo. E aqui, a expressão "colonialidade do poder"s é muito representativa do desenho planeado a partir do Sistema-Mundo Moderno/Colonial, que "articula os lugares

4 Aquilo que fica internalizado após o fim do colonialismo. Colonização do ser, do poder e do saber.

5 Se refere àquilo que restou da colonização. Colonização do ser, poder, saber e depois da natureza. 
periféricos da Divisão Internacional do Trabalho com a hierarquia étnico-racial global e com a inscrição de migrantes do Terceiro Mundo na hierarquia étnicoracial das cidades metropolitanas globais" (BALLESTRIN, 2013, p. 100). A situação colonial permanece e se reproduz no poder, no saber e no ser das zonas periféricas. Neste imbróglio, a globalização surge como um expoente anunciador de uma nova fase do capitalismo, ainda mais naturalizado nas relações mundiais, e possui um discurso de "uniformização, homogeneização e normalização" (MAGALHÃES, 2012, p. 15) centrado no indivíduo autônomo:

\begin{abstract}
Neste momento de globalização moderna, o mercado global cria padrões de comportamentos e valores uniformizados em escala global, fundamental para o sucesso do capitalismo global. Parcelas cada vez maiores de pessoas são convertidas ao credo do capitalismo: o individualismo e a competição permanente. Os cidadãos são convertidos em consumidores. Uma nova subjetividade é construída em escala global onde comportamentos e valores construídos por complexas relações sociais e econômicas históricas são naturalizados. $\mathrm{O}$ ser humano consumidor, egoísta e competitivo, construído pela modernidade, é naturalizado. Em outras palavras isto significa que as pessoas passam a perceber estes valores e comportamentos como se fossem naturais no ser humano, o que obviamente não é (MAGALHÃES, 2012, p. 26).
\end{abstract}

A globalização é envolvida de um discurso sedutor de igual oportunidade a todos, afinal, não existem mais barreiras e nem divisões em um mundo que está amplamente conectado: a "ordem capitalista aparece no novo milênio como a única forma de sociedade viável e, portanto, como o horizonte possível para sonhos de realização pessoal e esperanças de redenção coletivas." (CORONIL, 2005, p. 1). Na perspectiva homogênea e imparcial do globo, o capitalismo proveu uma ampla integração e apagamento das diferenças, onde as possibilidades são ilimitadas e estão ligadas ao mérito daqueles que querem chegar à modernidade metropolitana prometida pela Europa. Acontece que o que somos é processo histórico de uma história de periferia, exploração e expropriação. Como superar uma desigualdade que foi justamente o que ajudou a formular o capitalismo?

O que o capitalismo tenta fazer é ocultar a realidade de uma permanente submissão do outro, como uma dominação mais sofisticada do que acontecia no período colonial. A desigualdade está posta e se retroalimenta como uma fórmula do próprio sistema que possui várias camadas (dentro da própria subalternidade existem as elites e os periféricos, por exemplo) e não permite o seu desfazimento (MORENO, 2005). Embora não seja o foco do presente artigo $^{6}$, é central pontuar que a análise da formação do capitalismo colonial/

6 As questões sobre a relevância do gênero e da raça são muito mais complexas, profundas e estruturais do que como apresentado no presente trabalho, contudo, não podem deixar de ser mencionadas. 
moderno, e suas repercussões nos países periféricos, passa por um necessário pensamento interseccional de raça, gênero e classe. É nessas três instâncias que ocorrem as relações de "exploração/dominação/conflito" (BALLESTRIN, 2013, p. 101), articulando-se e produzindo uma diferença que tem como ponto de referência o capitalismo, branco e patriarcal. A dominação, portanto, opera por meio dessa lógica que faz com que quanto mais distante das características hegemônicas do sistema, mais precarizada seja a posição social do indivíduo e, em especial, a sua condição de trabalho (MIGUEL, 2018). As mulheres negras, por exemplo, que estão nesse local diametralmente oposto ao estabelecido pelo grupo dominante, ocupam a base da pirâmide do trabalho como reflexo de uma continuidade ideológica das estruturas de racismo e patriarcalismo coloniais, sendo inseridas no mercado de trabalho de maneira vulnerável e com baixos rendimentos (RATTS, 2006). Nesse mesmo sentido, uma pesquisa (2020) sobre mulheres entregadoras na cidade de Quito (Equador) concluiu que:

\begin{abstract}
Es así, que la situación de las mujeres está atravesada por um mayor número de vulneraciones y violencias, pero, además, las mujeres son diversas y se enfrentan a diversas opresiones. Con esta investigación, develo que el racismo, el acoso sexual, la división sexual del trabajo y la carga no remunerada del trabajo reproductivo son barreras para las mujeres, y a su vez, condiciones para mayor grado de violencia y precariedade (CORDERO, 2020, p. 364).
\end{abstract}

As empresas transnacionais são grande expoente de globalização, em que a desestabilização das fronteiras geográficas e políticas se dá por meio da financeirização do capital e diluição dos grandes conglomerados de fábrica pelos cantos do mundo onde as vantagens financeiras se mostrem mais atrativas. A ingerência das transnacionais em diversos territórios, aliada ao recrudescimento da atuação estatal (sob a ilusão de que é um Estado neutro, objetivo e democrático), cria uma atmosfera ausente de qualquer embaraço ao livre mercado. Nesse âmbito, o capital articula-se constantemente para estender o seu código de lucro/não-lucro para outros sistemas sociais (DE GIORGI, 2016), de modo que a globalização acontece como uma avalanche de uniformização que caracteriza e divide todos os indivíduos entre trabalhadores ou consumidores: o trabalho como um fim para o consumo e o consumo como um prêmio pertinente ao indivíduo que vence por meio do seu próprio esforço. O neoliberalismo, portanto, se apresenta como a política econômica ideal para a completa expressão e expansão do capitalismo, já que se transmutou em algo mais do que uma teoria econômica, mas se traduz em todo um modo de pensar o mundo que tem impacto direto nas relações de trabalho e de consumo. 


\section{TRANSNACIONAIS NA ECONOMIA DE COMPARTILHAMENTO}

A chamada "Economia de Compartilhamento", surgiu com uma proposta de disputa ao monopólio das grandes corporações sobre serviços caros e burocráticos, para dar mais ênfase à colaboração entre os iguais, priorizando o acesso em detrimento da propriedade, como uma alternativa mais econômica e sustentável (SLEE, 2017). Assim, por meio de amplo marketing, empresas que se tornaram gigantescas multinacionais espalharam-se por todo o globo em razão de seus preços baixos e do atrativo discurso de cooperação, democratização da propriedade e transparência (SCHOR, 2017). Foi construído, então, um "significado simbólico positivo" (SCHOR, 2017, p. 22) em torno do uso da tecnologia como um aspecto de transformação da relação de consumo, que foi capturado por diversos setores da economia (turismo, transporte, serviços pessoais e finanças, por exemplo). As empresas operam sob um discurso de que a sua função do mercado é apenas conectar os consumidores aos prestadores de serviço, em operações que são moldadas pelo próprio mercado e amparadas pela neutralidade e imparcialidade da tecnologia.

Contudo, a falta de regulação sobre a atividade destas empresas que atuam sem ter que responder aos diversos regramentos impostos ao mercado tradicional cria embates com outras empresas do mesmo setor ${ }^{8}$ e com o poder público ${ }^{9}$, ademais de uma série de discussões no que tange às normas concorrenciais ${ }^{10}$. Outrossim, as companhias se vendem às custas de um "falso universalismo" (SCHOR, 2017, p. 29) em relação ao acesso sobre os serviços que promovem: todo mundo terá a oportunidade de usufruir de uma hospedagem mais barata ou um serviço de transporte privado, por exemplo. As propagandas estão impregnadas da ideia de "conectar o mundo" e de que existe uma "comunidade global". Mas, de fato, todo mundo tem acesso aos serviços apresentados por esses aplicativos? Essas narrativas estão explícitas no site da Uber e do Airbnb, respectivamente:

Criamos oportunidades ao colocar o mundo em movimento. Quando as pessoas têm mobilidade, tudo é possível. As oportunidades surgem, as portas se abrem e os sonhos se tornam realidade. Nossa tecnologia,

7 Há grande disputa em torno da denominação deste mesmo fenômeno (gig economy, on-demand, crowdwork, crowdsource, economia - Uber). Contudo, o termo "Economia de Compartilhamento" será utilizado por estar mais presente na bibliografia utilizada, embora seja necessária a diferenciação entre a real "Economia de Compartilhamento" (comunitária, informal e intermediadora entre pares) e esse modelo econômico lucrativo que cria novas formas de consumo.

8 Ver: https://www.jornaldocomercio.com/_conteudo/economia/2019/11/713452-concorrencia-comairbnb-impacta-hotelaria.html.

9 Ver: https://g1.globo.com/mundo/noticia/2019/02/10/paris-entra-na-justica-contra-airbnb-e-pedemulta-de-125-milhoes-de-euros.ghtml.

10 Ver:https://valor.globo.com/empresas/noticia/2019/12/23/juiz-ordena-suspensao-de-servicos-douber-na-colombia.ghtml. 
que começou como uma simples forma de pedir viagens ao toque de um botão, já possibilitou bilhões de conexões entre pessoas no mundo todo ${ }^{11}$.

Nossa comunidade global e diversa é o que torna o Airbnb possível ${ }^{12}$.

Nossa comunidade global nunca falha em nos surpreender com suas histórias de gentileza e conexão. Nosso movimento \#OneLessStranger compartilha esses momentos de empatia e descoberta com o mundo inteiro $^{13}$.

Se essas empresas se apresentam atrativas, inclusivas e universais na questão do consumo, de outra ponta, as oportunidades são igualmente convidativas para aqueles que prestam o serviço. Nesse sentido, a proposta é de complementação de renda, liberdade na jornada de trabalho, superação das barreiras do mercado de trabalho locais, empreendedorismo e parceria entre os prestadores de serviço e a plataforma on-line. As empresas se definem como empresas de tecnologia que atuam como intermediárias entre consumidores e prestadores de serviço (ANTUNES; FILGUEIRAS, 2020, p. 30). Nesse encontro, portanto, existe oportunidade, igualdade entre as partes, imparcialidade do mercado e neutralidade da tecnologia. É o que se observa no site da Uber Eats:

Com o Uber Eats, entregadores parceiros se cadastram e, após serem ativados, começam a receber chamadas de restaurantes e a conectar pessoas às suas comidas favoritas ${ }^{14}$.

Faça entregas com a Uber. Você escolhe quando quer ganhar ${ }^{15}$.

Não obstante, na prática, esse modelo econômico tornou-se controvertido em relação ao discurso que apresenta. O que se vê são empresas centradas em tecnologia que recebem altos investimentos de grandes instituições financeiras e fundos de capital de risco para operarem através de uma "ampla agenda de desregulamentação em busca da riqueza privada” e encorajando mais formas

11 Ver:https://www.uber.com/br/pt-br/about/?utm_campaign=CM2041229-search-googlebrand_25_574_BR-Brasilia_rider_web_ren_cpc_ptBR_Brand_BMM_\%2Buber_aud $967640029812 \%$ 3Akwd38545560932_467357377672_115054950652_b_c\&um_source=AdWords_Brand.

13 Ver: https://www.airbnb.com.br/diversity.

14 Ver: https://www.uber.com/br/pt-br/deliver/.

15 Ver: https://www.uber.com/a/signup/drive/deliver/. 
de consumismo (SLEE, 2017, p. 60). Assim, tais empresas travestem-se de um discurso de comunitarismo, informalidade, promessa de complementação de renda e empreendedorismo para se colocar nas zonas limítrofes da regulação estatal, em especial no que se refere à incidência de proteção do trabalho e de suas normas reguladoras, com pouca ou nenhuma responsabilidade sobre as relações que estabelecem com os seus "prestadores de serviço" (SLEE, 2017, p. 145).

Os trabalhadores, na realidade, encontram-se em um limbo entre vínculo de emprego e autonomia, vez que não se estabelece uma relação de emprego clássica entre a empresa e o trabalhador, ao mesmo tempo que são impostos mecanismos de controle e vigilância eletrônico e difuso (CARELLI; CASAGRANDE; OITAVEN, 2018, p. 30), o que tenciona por um elastecimento ou mutação de sentido dos clássicos elementos caracterizadores do contrato de trabalho, principalmente no que se refere à subordinação jurídica e alteridade como ônus do empregador (CARELLI; CASAGRANDE; OITAVEN, 2018, p. 33). Nessa lógica, os postos de trabalho são configurados para serem caracterizados como autônomos e fruto de empreendedorismo, fundados na imagem do trabalhador como um parceiro e parte do sistema, resultante de seu esforço individual e congratulado por seus "méritos" individuais, que se habilita na venda livre de seu trabalho em um mercado competitivo. ${ }^{16}$

Um dos resultados mais explícitos desse trajeto pela construção de novas formas de contrato de trabalho através do uso das tecnologias disruptivas é o trabalhador que faz entregas intermediado por um aplicativo de celular: percorre a cidade (em bicicleta ou moto) com uma entrega solicitada através do aplicativo de celular, não possui vínculo de emprego com a empresa de onde vem o pedido, com a pessoa que fez o pedido e nem com o aplicativo que intermediou essa transação. Isso porque, enquanto o site do aplicativo de entrega $\operatorname{Rappi}^{17}$, por exemplo, traz como chamariz a novos entregadores as promessas de "fique online quando quiser"; "fature alto" e "nós estamos construindo uma América Latina melhor", a pesquisa realizada pela BBC News Brasil ${ }^{18}$ aponta que os trabalhadores entrevistados "relataram fazer jornadas de mais de 12 horas diárias, trabalhar muitas vezes sem folgas e até dormir na rua para emendar um horário de pico no outro, sem voltar para casa", ademais de não receberem equipamento de proteção e serem estimulados por prêmios e preços especiais dados pelos aplicativos para se distribuir pela cidade conforme estipulado pelo algoritmo da empresa.

Os impactos dessa reconfiguração do mercado de trabalho causado pelas tecnologias disruptivas são enormes e palco de grande disputa. Na Califórnia, por exemplo, em meio a um grande conflito com em torno do enquadramento dos motoristas (se autônomos ou funcionários) a Uber e a Lyft já gastaram cerca de 186

16 Ver: CHAUI, Marilena. A tragédia neoliberal e a meritocracia. Disponível em: https://www.youtube. com/watch? $\mathrm{v}=5$ jNea8b3hUE. Acesso em 30/08/19.

17 Ver:https://soyrappi.com/?utm_source=appuser\&utm_medium=applk\&utm_campaign=rt\&_ $\mathrm{ga}=2.119145545 .1545991713 .1566846327-109650324.1566846327$.

18 Disponível em: https://epocanegocios.globo.com/Empresa/noticia/2019/05/dormir-na-rua-pedalar30-km-e-trabalhar-12-horas-por-dia-rotina-dos-entregadores-de-aplicativos.html. 
milhões de dólares em financiamento da Proposta $22^{19}$, que tem o objetivo de isentar as empresas de terem de incorporar os motoristas ao seu quadro de funcionários, em um movimento de resposta ao Projeto de Lei 5, aprovado ao final do ano passado, que estipulou requisitos a serem demonstrados por essas empresas para afastar o vínculo de emprego. Esses requisitos são conhecidos como "Teste do $\mathrm{ABC}$ ”:

SEC. 2 A Seção 2750.3 é adicionada ao Código do Trabalho, para ler:

2750,3. (a) (1) Para efeitos das disposições deste código e do Código de Seguro Desemprego, e para as ordens salariais da Comissão de Bem-Estar Industrial, uma pessoa que fornece trabalho ou serviços em troca de remuneração deve ser considerada um empregado, em vez de um contratante independente, a menos que a entidade contratante demonstra que todas as seguintes condições foram satisfeitas:

(A) A pessoa está livre do controle e direção da entidade contratante em relação à execução da obra, tanto no âmbito do contrato para a execução da obra como de fato.

(B) A pessoa executa trabalho que está fora do curso normal dos negócios da entidade contratante.

(C) A pessoa está habitualmente envolvida em um comércio, ocupação ou negócio independente estabelecido da mesma natureza que aquele envolvido no trabalho executa ${ }^{20}$.

O que a disputa na Califórnia sinaliza é para o quão grande são essas empresas e quanto dinheiro estão dispostas a investir para sustentar o discurso de autonomia e empreendedorismo dos trabalhadores. As propostas intimistas de colaboração entre iguais da Economia de Compartilhamento, que é a filosofia que carrega o sucesso destes aplicativos, entram em choque com a realidade de grandes corporações, geridas por amplo capital financeiro, que tensionam com a coletividade de trabalhadores insatisfeitos com as condições de trabalho as quais são submetidos. Nesse ponto, o expoente da argumentação é a geração de postos de trabalho proporcionada pelo aplicativo que deve ser visto como

19 Ver: https://www.nytimes.com/2020/10/22/us/california-prop-22.html.

20 Ver: https://leginfo.legislature.ca.gov/faces/billCompareClient.xhtml?bill_id=201920200AB5. 
uma oportunidade a ser aproveitada por aqueles que procuram alguma (ou complementação de) renda:

\begin{abstract}
A decisão de hoje significa que se os eleitores não disserem Sim na Proposta 22, os motoristas de caronas serão impedidos de continuar a trabalhar como contratados independentes, deixando centenas de milhares de californianos sem trabalho e provavelmente fechando o serviço de caronas em grande parte do estado. Acrescentou um portavoz do Uber. ${ }^{21}$
\end{abstract}

Embora não seja o foco deste artigo, os parâmetros definidos pelo Projeto de Lei 5 são bastante interessantes diante da necessidade de contenção das condições precárias que atingem a multidão de trabalhadores que colocam sua força de trabalho à disposição destas plataformas ${ }^{22}$, conforme se verá a seguir.

\title{
5. PRECARIZAÇÃO E SUBALTERNIDADE
}

Ao longo da história, as constantes articulações do capital para gerar novas formas de valor a partir da reestruturação da cadeia de produção tem tensionado no sentido de estender o seu código de lucro/não-lucro para outros sistemas sociais e fugir dos vínculos do trabalho assalariado historicamente constituídos. As relações de trabalho, portanto, sofrem profundas modificações e mudança de sentido quando os objetivos do capital são absorvidos pelo seu sistema, retirando o bem estar e a dignidade do trabalhador da sua centralidade (DE GIORGI, 2016, p. 58).

Essa modificação nas relações de trabalho torna-se ainda mais dinâmica com o uso da tecnologia que cria, extingue e altera as vagas de trabalho clássicas e o modo de prestação de serviço (SOLIMANI; FILHO, 2017), ao fragmentar a produção e pulverizar espacial e temporalmente o próprio modo de desenvolvimento do trabalho. Além disso, impulsiona o setor de serviços para a centralidade das cadeias produtivas (SCHWARTZ, 1996, p. 148), constituídas com postos de trabalho cada vez mais heterogêneos, individuais e distantes dos referenciais que fundavam a identidade de classe e as tradicionais formas de luta de classe (ANTUNES, 2018). Entretanto, a inserção da tecnologia do mercado de trabalho se dá sob o discurso de ser potencializadora da "integração" promovida pela globalização e geradora de oportunidades de trabalho para a mão-de-obra

21 Ver: https://www.theverge.com/2020/10/22/21529644/uber-lyft-lose-appeals-court-driver-employees.

22 Em 2019, no Brasil, eram quase 4 milhões de trabalhadores autônomos que se utilizavam das plataformas como fonte de renda (Ver: https://economia.estadao.com.br/noticias/geral,aplicativoscomo-uber-e-ifood-sao-fonte-de-renda-de-quase-4-milhoes-de-autonomos,70002807079). 
ociosa. É um cenário de ampla desregulamentação do mercado de trabalho, legitimado pelo Estado Moderno neoliberal que atua e se omite conforme a conveniência do capital, já que estes possuem uma relação de interdependência, e o resultado é a crescente precarização nas condições de trabalho e abandono dos trabalhadores, tendo como pano de fundo a permanência de algumas das características da exploração colonial: Um discurso meritocrático aliado a uma invisibilização do outro como sujeito de direitos.

O trabalho intermediado pela tecnologia obscurece a presença dos elementos caracterizadores do vínculo de emprego, em especial a subordinação, e oculta ambos os lados da prestação de serviço porque nem o trabalhador e nem o empregador pode ser exatamente identificado. E é desse ponto que se aproveita o discurso de neutralidade da tecnologia disruptiva: ao não existir empregador ou direcionamento do serviço, já que o trabalhador pode escolher como e onde quer trabalhar, o ônus dos ganhos estão concentrados somente no seu mérito individual, que precisa desenvolver estratégias de vida (fazer a gestão de tempo e recursos) para vencer as barreiras naturais do mercado, e tornando-se competente e competitivo. Ao fim, é o trabalhador que assume os riscos da própria atividade. Os esforços são no sentido de não apenas negar que os trabalhadores são de fato trabalhadores, mas também de "disseminar o espírito empreendedor" (BARBOSA, 2011, p. 135), como fazem empresas que operam por aplicativos ao prometerem autonomia e liberdade.

A responsabilidade sobre o êxito no trabalho é do trabalhador e a responsabilidade sobre a eventual condição de desemprego também o é. Cabe ao indivíduo se empenhar para garantir um bom desempenho em meio a um mercado cada vez mais competitivo (BARBOSA, 2011, p. 131), já que ao capitalismo cabe colocar à disposição do indivíduo oportunidades imperdíveis de geração de renda e liberdade financeira. Inclusive, o binômio direito versus trabalho é colocado na centralidade desse debate quando ao trabalhador é oferecido qualquer tipo de ocupação, vez que "é melhor menos direitos e [mais] emprego do que todos os direitos e desemprego." ${ }^{23} \mathrm{Ou}$ seja, os direitos trabalhistas podem ser deixados de lado em troca de postos de trabalho, independentemente de quais forem as condições desse trabalho. E os aplicativos surgem como uma chance irrecusável de o indivíduo se inserir na lógica de trabalho-consumo que molda a sociedade capitalista.

A propaganda que o capitalismo faz de si mesmo é o que alimenta o seu papel central no Sistema-Mundo atual. Imbuído do ego do colonizador, o sistema se vende como uma razão imparcial (fruto do encontro das vontades de indivíduos autônomos) e inegável, onde o sucesso reside no esforço individual e é proporcional às recompensas que recebe. $\mathrm{O}$ foco é ser tão desenvolvido quanto os países de capitalismo central e os meios para isso são os postos de trabalho oferecidos por empresas transnacionais que têm sede nestes mesmos países. Por

23 Leia mais em: https://veja.abril.com.br/politica/para-bolsonaro-e-melhor-menos-direitos-trabalhistasque-perder-o-emprego/. 
meio desse trabalho é que o indivíduo pode se inserir no padrão de consumo ocidental. Como recusar tais ferramentas de capacitação rumo à modernidade?

Para Moreno (2005), as promessas de inclusão e desenvolvimento feitas pelo capitalismo desempenham funções essenciais para a sua hegemonia: sacralizar o sistema e culpabilizar as vítimas. Não há espaço para questionamento quando o indivíduo é responsável pelo próprio sucesso, a culpa ocupa o lugar da inconformidade. Um trecho que é muito representativo dessa relação:

No dia 28 de janeiro de 1999 fui convidado, como comentarista, a um seminário sobre avaliação do programa de capacitação de jovens excluídos do sistema educativo que promove o Ministério da Família. Analisaram-se importantes e sérias pesquisas a respeito do tema. Todas se encaminhavam a estudar as condições dos excluídos; nenhuma as condições dos agentes de exclusão. E isso, não obstante servir para constatar que mesmo aqueles jovens já capacitados dificilmente encontravam um modo de integrar-se no mercado de trabalho. As conclusões coincidiam em que se necessitava de maior e melhor capacitação e, em todo caso, aperfeiçoamento do programa. A capacitação transforma-se, assim, num processo infinito em que os jovens jamais estarão capacitados e sempre serão culpados por sua situação (MORENO, 2005, p. 90).

É na atual Divisão Internacional do Trabalho, reforçada pela ampla inserção da tecnologia no mercado, que se evidenciam as precarizações herdadas da época colonial. O desemprego estrutural dos países periféricos é o perfeito encaixe para a lógica de constante ampliação do lucro. $\mathrm{O}$ mercado de trabalho está inserido em um contexto capitalista que se utiliza da lógica do desemprego estrutural para a manutenção da pouca oferta de postos de trabalho em detrimento da demanda, o que gera uma desvalorização do trabalhador ao ter que se submeter a quaisquer condições de trabalho por estar sempre rodeado pela ameaça do desemprego. Nesse sentido, além de disciplinador das forças de trabalho, uma vez que é constante o risco de substituição, o desemprego também faz a divisão entre os que estão incluídos e os que estão excluídos do mercado de trabalho formal. Os excluídos, as empresas transnacionais tratam de incorporar ao seu contingente de mão-de-obra disponível para desempenhar o que Abílio (2020) entende por "trabalho amador", um trabalho sem identidade profissional e permanentemente tratado como uma "oportunidade de complementação de renda".

Os aplicativos têm à sua disposição uma massa de trabalhadores invisíveis e despersonificados enquanto sujeitos de direitos, desempenhando tarefas por meio de uma relação que não é de vínculo de emprego e nem de plena autonomia. O controle se dá por meio de um gerenciamento algorítmico que conduz o modo de prestação de serviço dos trabalhadores em um sistema de recompensas e punições para o cumprimento dos objetivos traçados pelas empresas. Como as 
regras de controle não são claras, qualquer possível vínculo de emprego se oculta atrás da suposta neutralidade da tecnologia e da narrativa de empreendedorismo. Alguns relatos de entregadores exprimem que as inseguranças do trabalho andam em conjunto com alguma ingerência das plataformas:

Você vai até achar estranho de eu falar só Loggi, hoje eles conquistaram o mercado, tanto que você tem que trabalhar até meia-noite, a carga horária aumentou... antigamente você tinha meta, eu particularmente e vários amigos meus, tinha meta de $\mathrm{R} \$ 300$ por dia... "Eu vou fazer, tipo, até às 6 h, no máximo até 7 h”... você conseguia... hoje não. É o que a gente fala, o cara quando não tem família, é solteiro, é diferente, ele trabalha até a hora que ele quiser, então hoje a Loggi está praticamente obrigando você ficar até meia-noite, 11 horas na rua. Antes tinha muita entrega, não tinha tanto estresse, não era tão nervoso, hoje em dia você cansa mais andando de moto, gastando, sem ganhar nada do que trabalhando. Por isso que eu falo, nesse último ano agora, pelo amor de Deus, o stress, nervoso, cansaço, as dores físicas nas costas, mental, piorou, porque você está andando mais de moto do que fazendo serviço, porque você tem que ficar rodando (ABÍLIO, 2020, p. 117).

[...] se o tempo estiver chuvoso, igual hoje de manhã, eles mandam mensagens 9 horas: "das $10 \mathrm{~h}$ até as $13 \mathrm{~h}$, fazendo 8 pedidos delivery você ganha mais $\mathrm{R} \$ 50$ ”. Se você não fizer você não ganha o bônus (ABÍLIO, 2020, p. 119).

Eu, você e outro motoboy estamos trabalhando lá, são 8 pedidos, eu e você fizemos 7 , o outro motoboy fez 4 . Para quem eles vão jogar a entrega? Para o outro motoboy (ABÍLIO, 2020, p. 119).

A realidade é que as empresas definem os preços, as entregas, a oferta e a demanda, ao organizar a distribuição dos trabalhadores pela cidade, e externalizam todos os custos ao trabalhador (responsabilidade pela jornada de trabalho e ferramentas de trabalho), remunerando-o somente por aquilo que ele produz. As jornadas de trabalho são extensas e há uma dissolução entre a linha que separa o que é ou não trabalho, vez que o trabalhador se encontra permanentemente à disposição para quando for "acionado" pelo aplicativo que passa a "moldar sua vida toda à demanda (ou possibilidade de encontrá-la) por seus serviços" (ANTUNES; FILGUEIRAS, 2020, p. 36).

Há um total manejo da mão-de-obra pelas plataformas que "controlam todo o processo, determinam os formatos exatos dos contratos de trabalho, pagam, mobilizam, ameaçam e dispensam" (ANTUNES; FILGUEIRAS, 2020, p. 38). Deste modo, um amplo contingente de trabalhadores é visto apenas como força de trabalho 
que, submetidos a uma situação de negação da "condição de assalariamento" (ANTUNES; FILGUEIRAS, 2020, p. 33), não gozam de qualquer direito, e transferem capital para as empresas globais em troca de baixos rendimentos.

A vigilância é ampla, constante e há um domínio dos dados cadastrados na plataforma, de toda a rotina de trabalho dos entregadores e das avaliações feitas pelos clientes (ENGLERT; WOODCOCK; CANT, 2020). Essas informações possibilitam uma percepção panorâmica dos padrões de consumo que torna ainda mais assertiva a mobilização dos trabalhadores por meio dos estímulos de premiações e punições. Ou seja, na prática, não há possibilidade real de superação por meio do esforço individual que é invisibilizado e controlado em meio a uma multidão, vista como homogênea. A subalternização do trabalhador é a única regra que está clara na gestão empresarial exercida por meio de algoritmo.

Em um abandono que é multidimensional ${ }^{24}$, ao trabalhador resta lidar com as investidas neoliberais e encontrar no coletivo a resistência à ideologia do mérito e da individualidade. Na Cidade do México, os entregadores criaram o coletivo \#NiUnRepartidorMenos como reação à morte de José Manuel Matías, entregador atropelado em 2018 durante a entrega de um pedido. O coletivo tenta construir uma rede de apoio para superar as dificuldades do trabalho precário e do completo descaso das empresas frente à vida dos trabalhadores. O discurso de autonomia já não mais convence estes trabalhadores que desejam ser tratados como sujeitos possuidores de direitos:

¿Qué cabe en una mochila de un repartidor? 60 kilos de compras, 10 cajas de pizza grandes, 8 costales de hielo, el favor de último momento como dejar unas llaves, comprar un regalo, pasear a tu perro. ¿Qué no entra? Acceso a servicios de salud, incapacidad en caso de accidentes, un ingreso relativamente estable, la posibilidad de irse de vacaciones con paga, un esquema de ahorro, una capacitación mínima en seguridade. Como repartidores queremos decirte que la realidad detrás de tu pedido es esa que no cabe en la mochila. No es la libertad ni la autonomía que anuncian con brillantina las plataformas bajo el lema "Tú decides. Eres tu propio jefe". Tampoco es el bonito anuncio de "dale volumen a tu música favorita y disfruta el recorrido por la ciudad". La "libertad" que nos conceden sí involucra adrenalina, pero es más parecida a una ruleta rusa. Es no saber si la zona a las que vamos es tranquila o una zona roja. Es saber que si te mueres y no estás conectado nadie va a responder por ti, como le pasó a nuestra compañera Ximena Callejas. Es el azar extremo, el que te impide saber con cuánto acabarás en la semana y cuánto de eso vas a invertir en una reparación, en una refacción, en tu salud o en una consulta médica. Es ese tipo de juego que te motiva a ponerte metas mínimas de ingreso por día, sin saber si las vas a llegar a cumplir porque se cruza el clima, las quincenas, vacaciones, días festivos o las marchas. Pero aún así le

24 "O abandono multidimensional dos entregadores que trabalham para aplicativos pode ser conceituado como ausência jurídica, estatal e social decorrente de sua inserção laborativa fragilizada na Economia da Tecnologia. 
entras al juego y estás dispuesto a trabajar sin parar hasta 12 horas por día y arriesgar tu vida en la lluvia por 20 pesos extra. Le llaman autoexplotación, pero de ello depende un "mejor" ingreso ${ }^{25}$.

No Brasil, em meio à pandemia de Covid-19 que expôs e ampliou as precárias condições de trabalho destes entregadores, houve grande mobilização para pressionar as empresas por, principalmente, aumento das taxas, suspensão dos bloqueios sem justificativa, segurança, fornecimento de alimentação e equipamento de proteção individual ${ }^{26}$. Com amplo apoio popular, houve paralização dos entregadores nos dias $1^{\text {a }}$ e 25 de julho. Embora tenha havido algumas pequenas concessões por parte das empresas, uma das principais estratégias foi investir em propagandas que reforçassem a narrativa de parceria, relacionamento e troca ${ }^{27}$ promovidos pelo aplicativo. Nada mais simbólico para corroborar a ideia de que o capitalismo vive de propaganda (dele mesmo) e de promessas. Como tensionar com um sistema que se pretende como o único concebível? O capitalismo global, portanto, conserva a relação de expropriação da vida e ocultamento do sujeito em troca de lucro (agora para o capital financeiro transnacional) sob a narrativa de mérito do indivíduo, como uma herança da colonização do Ocidente sobre o resto do mundo. Não há possibilidade de negação ao sistema, vez que, ou o indivíduo se incorpora a ele no lugar que lhe cabe, ou está fadado a ser excluído das possibilidades de consumo e de trabalho. Agora, com uma submissão por meio da tecnologia, a multidão de mão de-obra do Sul global continua à disposição dos países de capitalismo central, tal qual na época das Colônias, embora com outra modalidade de exploração.

\section{CONSIDERAÇÕES FINAIS}

A história da humanidade que é contada a partir de uma visão eurocêntrica é uma história de divisão entre vitoriosos e derrotados, sustentada por uma perspectiva de mérito individual do homem moderno e do ocultamento do outro. A modernidade é pregada como um expoente civilizatório que proporciona à humanidade um novo estágio ao desenvolvimento do ser humano. Nesse processo, as instituições constituíram-se a partir de uma visão capitalista, branca e ocidental, expandindo-se e acomodando as outras formas de vida não-europeias como uma periferia do "Sistema-Mundo" que se formatava. A história contada, contudo, omite o protagonismo dos países periféricos que, em um enlace de exploração do trabalho e da natureza, foram fundamentais para a formação do sistema capitalista e a sua consolidação como sistema hegemônico.

Ver: https://nosotrxs.org/en-tu-pedido-va-mi-vida/.

Ver: https://www.istoedinheiro.com.br/entregadores-de-aplicativo-planejam-greve-para-1-de-julho/.

Ver: https://www.jornaltornado.pt/o-ifood-e-lindo-na-propaganda/. 
Falar sobre o capitalismo é pensar sobre um aprofundamento repaginado de alguns dos principais elementos que guiaram o período colonial e dividiram os papéis do centro e da periferia: a ausência de reconhecimento do outro como sujeito de direitos e a narrativa centrada em um individualismo meritocrático como forma de sacramentalizar o sistema. Embora não haja um domínio político e militar, os países "não-desenvolvidos" persistem reclusos em uma colonialidade que impossibilita o vislumbre de qualquer outra forma de viver no mundo. A concentração de riquezas e o fluxo de capital ainda se dá da periferia para o centro do globo, operado por meio da dialética tripla de trabalho, natureza e capital.

O neoliberalismo e a globalização se colocam como modelos de existência insuperáveis que, ao mesmo tempo que propagandeiam o capitalismo global como gerador de oportunidades vinculadas ao mérito individual, criam uma atmosfera de homogeneização mundial sobre os padrões de comportamentos e valores, que está intimamente relacionado ao vínculo do trabalho com o consumo: o fim do trabalho é o consumo e o consumo é o resultado de um mérito individual conquistado através do trabalho. As transnacionais, portanto, se posicionam mundialmente como reforço ao ideal de status de igualdade alcançada através da globalização, gerando postos de trabalho e distribuindo seus produtos e serviços para que qualquer pessoa possa ter acesso. Como se recusar a entrar nesse sistema? A propaganda é atrativa e chega aos consumidores e trabalhadores como forma de "Economia de Compartilhamento", como um rejunte da tecnologia com a prestação de serviço que oferece mais oportunidades no mercado de trabalho e formas mais conscientes de consumo.

A realidade, contudo, é uma globalização neoliberal que gera uma falsa sensação de desenvolvimento econômico, mas reproduz a Divisão Internacional do Trabalho que teve as raízes formadas nas relações coloniais, com repercussões diversas e profundas nos âmbitos de gênero e de raça. A expropriação da vida humana por meio do trabalho barato, em especial a vida humana localizada nos países periféricos, é o que sustenta o lucro das grandes companhias. As plataformas digitais de entrega podem ser apontadas como grandes representantes desse cenário: desligadas de qualquer vínculo de emprego, as empresas de aplicativo de entrega se colocam atrás da tecnologia para afirmar pela existência de uma multidão empreendedora que, por seu esforço individual, precisa superar as barreiras do mercado de trabalho para complementar (ou ganhar alguma) renda. Responsáveis pelo controle da sua jornada de trabalho, ganhos, equipamento de proteção individual e sem ter total conhecimento das regras impostas pelo algoritmo, a massa de mão-de-obra disponível se desloca pelas cidades (de moto ou de bicicleta) sem ser reconhecida enquanto sujeito individual, possuidor de direitos e de concepções de mundo. O trabalhador é visto por meio do algoritmo (que envia comandos de acordo com os objetivos da empresa) e tem como estímulo a promessa feita pelo capitalismo de que o esforço individual é retribuído com acesso aos padrões de consumo. 
A subalternização dos países periféricos é mantida estruturalmente pelas instituições capitalistas, inclusive os Estados, com os mesmos elementos com a qual foi concebida no período colonial. A diferença é só como estes elementos se apresentam: agora a tecnologia e a globalização são utilizadas para despersonificar o outro, apagado em meio à uma multidão uniforme, e o discurso do empreendedorismo coloca sobre o trabalhador a responsabilidade do seu próprio sucesso em um sistema em que o fracasso é a regra e a vitória está nos ideais do homem moderno. A relação direta entre trabalho e consumo que é prometida pelo capitalismo, mas nunca concretizada, está bem representada por uma música cantada por Zé Geraldo, que nos faz pensar sobre o fardo que é carregar a herança colonial do Sistema-Mundo Moderno como única forma possível de viver no mundo:

(...) Tá vendo aquele colégio, moço?

Eu também trabalhei lá

Lá eu quase me arrebento

Fiz a massa, pus cimento

Ajudei a rebocar

Minha filha inocente

Vem pra mim toda contente

Pai, vou me matricular

Mas me diz um cidadão

Criança de pé no chão

Aqui não pode estudar

Essa dor doeu mais forte

Por que é que eu deixei o norte?

Eu me pus a me dizer

Lá a seca castigava

Mas o pouco que eu plantava

Tinha direito a comer (...)

(Cidadão - Zé Geraldo. Composição: Lucio Barbosa)

\section{REFERÊNCIAS}

ABILIO, Ludmila Costhek. Uberização: a era do trabalhador just-in-time? Estudos Avançados. São Paulo, v. 34, n. 98, abr. 2020, p. 111-126. 
ALVES, Amauri Cesar; BAGNO, Lorena Isabella Marques; GONÇALVES, Nicolle. Entregas mediadas por aplicativos e o mito do empreendedor de si mesmo na pandemia do Coronavírus. Revista Direito. UnB, Brasília, v. 04, n. 02, 2020, pp. 85-116.

ANTUNES, Ricardo. O privilégio da servidão: O novo proletariado de serviços na era digital. São Paulo: Boitempo Editorial, 2018.

ANTUNES, Ricardo; FILGUEIRAS, Vitor. Plataformas digitais, Uberização do trabalho e regulação no Capitalismo contemporâneo. Contracampo, Niterói, v. 39, n. 1, abr./jul. 2020, pp. 27-43.

BALLESTRIN, Luciana. América Latina e o Giro Decolonial. Revista Brasileira de Ciências políticas, Brasília, n. 11, 2013, pp. 89-117. Disponível em: https:// www.scielo.br/pdf/rbcpol/n11/04.pdf.

BARBOSA, Attila Magno et al. O empreendedor de si mesmo e a flexibilização no mundo do trabalho. Revista de Sociologia e Política, v. 19, n. 38, 2011, pp. 121-140.

CARELLI, Rodrigo de Lacerda; CASAGRANDE, Cássio Luís; OITAVEN, Juliana Carreiro Corbal; Empresas de transporte, plataformas digitais e a relação de emprego: um estudo do trabalho subordinado sob aplicativo. Brasília: Ministério Público do Trabalho, 2018.

CORDERO, Kruskaya Hidalgo. Habitando las economías de plataforma. El ser mujer repartidora en Uber Eats y Glovo en Quito. Akademía. Revista Internacional y Comparada de Derechos Humanos. v. 3, n.20, 2020, pp. 329-372.

CORONIL, Fernando. Natureza do pós-colonialismo: do eurocentrismo ao globocentrismo. In: LANDER, Edgardo (org.). A colonialidade do saber: eurocentrismo e ciências sociais. Perspectivas latino-americanas. Coleccin Sur Sur. Ciudad Autónoma de Buenos Aires, Argentina: CLACSO, 2005, pp. 55-62. Disponível em: http://biblioteca.clacso.edu.ar/ar/libros/lander/pt/lander.html.

DE GIORGI, Raffaele. O futuro do trabalho e o seu Direito. Revista Direito Mackenzie, São Paulo, v.11, n.1, 2017, pp. 52-72.

DUSSEL, Enrique. 1492 - El encubrimiento del otro: hacia el origen del mito de la modernidad. La Paz: UMSA. Facultad de Humanidades y Ciencias de la Educación Plural Editores, 1994. Disponível em: http://bibliotecavirtual.clacso. org.ar/clacso/otros/2011121 8114130/1942.pdf

ENGLERT, Sai; WOODCOCK, Jamie; CANT, Callum. Operaísmo digital: tecnologia, plataformas e circulação das lutas dos trabalhadores. Fronteiras Estudos Midiáticos. V. 22, n. 1, 2020. 
MAGALHÃES, José Luiz Quadros de. O estado plurinacional e o direito internacional moderno. Curitiba: Juruá, 2012, pp. 122.

MAGNO, Attila; BARBOSA, Silva. O empreendedor de si mesmo e a flexibilização no mundo do trabalho. Revista de Sociologia e Política, v. 19, n. 38, 2011, pp. 121-140.

MIGNOLO, Walter D. Desobediência epistêmica: a opção descolonial e o significado de identidade em política. Cadernos de Letras da UFF - Dossiê: Literatura, língua e identidade, n. 34, 2008, pp. 287-324. Disponível em: http:// professor.ufop.br/tatiana/classes/ppgd-pluralismoepistemol\%C3\%B3gico/ materials/desobedi\%C3\%AAnciaepist\%C3\%AAmica-walter-mignolo.

MIGUEL, Luis Felipe. Dominação e resistência: Desafios para uma política emancipatória. São Paulo: Boitempo Editorial, 2018.

MORENO, Alejandro. Superar a exclusão, conquistar a equidade: reformas, políticas e capacidades no âmbito social. In: LANDER, Edgardo (org.). A colonialidade do saber: eurocentrismo e ciências sociais. Perspectivas latinoamericanas. Coleccin Sur Sur. Ciudad Autónoma de Buenos Aires, Argentina: CLACSO, 2005, pp. 88-94. Disponível em: http://biblioteca.clacso.edu.ar/ar/ libros/lander/pt/lander.html.

RATTS, Alex. Eu sou atlântica: sobre a trajetória de vida de Beatriz Nascimento. São Paulo: Imprensa Oficial, 2006.

SCHOR, Juliet. Debatendo a Economia do Compartilhamento. In: ZANATTA, Rafael A. F.; DE PAULA, Pedro C. B; KIRA, Beatriz. Economias do Compartilhamento e o Direito. Curitiba: Juruá, 2017, pp. 21-40.

SCHWARTZ, Yves. Trabalho e valor. Tempo social; Rev. Sociol. USP, São Paulo, n.8, p. 147-158, 1996, pp. 148.

SLEE, Tom. Uberização: A nova onda do trabalho precarizado. São Paulo: Editora Elefante, 2017, pp. 320. Tradução de: João Peres.

SOLIMANI, Carlos Henrique; FILHO, Adalberto Simão. As tecnologias disruptivas: os impactos no direito coletivo e individual do trabalho. In: Congresso Brasileiro de Processo Coletivo e Cidadania, n.5, 2017, Ribeirão Petro. Anais... Recuperado de http://revistas.unaerp.br/cbpcc/article/view/979.

WALLERSTEIN, Immanuel. O universalismo europeu: a retórica do poder. São Paulo: Boitempo, 2007, pp. 146. ISBN: 978-85-7559-097-3. 


\title{
THE EXPLORATION OF DELIVERY MAN AS AN EXPRESSION OF GLOBAL AND COLONIZING CAPITALISM: SOME INITIAL CONSIDERATIONS
}

\begin{abstract}
In an analysis of the condition of exploration of the delivery man, the present work aims to outline some initial reflections on two elements that connect global capitalism, materialized in transnational companies, to the period of colonization of the Americas: the expropriation of the rights of the other and the discourse of meritocratic individualism. For this purpose, taking as a starting point the concepts of "World System" and "Modernity", capitalism and globalization will be characterized as a reformulated continuity of what was established in the colonial period, with direct effects on the current International Labor Division. The hypothesis is that colonial exploitation of peripheral countries occurs through the performance of transnational companies that take advantage of the vast labor available to extract profit and direct the working mass towards achieving their goals. The case of deliverers will be used as a reference for the analysis of the practical expression of neoliberal capitalism in the Global South: research was made invisible in their rights, at the same time that they are inserted in a dynamic of apparent autonomy, competent for its success and failure. On the other hand, as application companies that stand behind a narrative of technology neutrality and homogenizing globalization. Without pretending to exhaust the theme, the main point is to reflect on the permanent expropriation of the rights of the other and the discourse of meritocratic individualism, which accompany the dialectic of the center and the global periphery, are fundamental characteristics of the creation of capitalism itself, germinated from the colonizing relationship and colonized.
\end{abstract}

KEYWORDS: Application-mediated worker. Global capitalism. Coloniality. Sharing economy. Precarious work.

\section{LA EXPLOTACIÓN DEL REPARTIDOR COMO EXPRESIÓN DEL CAPITALISMO GLOBAL Y COLONIZADOR: ALGUNAS CONSIDERACIONES INICIALES}

RESUMEN: TEn un análisis de la condición de explotación del repartidor de aplicaciones, el presente trabajo tiene como objetivo buscar algunas reflexiones iniciales acerca de dos elementos que conectan el capitalismo global, materializado en las empresas transnacionales, con el período de colonización de las Américas: la expropiación de los derechos del otro y el discurso del individualismo meritocrático. Por tanto, teniendo como punto de partida los conceptos de "Sistema Mundial" y "Modernidad", el capitalismo y la globalización se caracterizarán como una continuidad reformulada de lo establecido en el período colonial, con impactos directos sobre la actual División Internacional del Trabajo. La hipótesis es que la explotación colonial de los países periféricos se mantiene por medio de la actuación de las empresas transnacionales que aprovechan de la amplia mano de obra disponible para extraer ganancias y orientar a la masa trabajadora hacia el cumplimiento de sus objetivos. El caso de los repartidores se utilizará como referencia para el análisis de la expresión práctica del capitalismo neoliberal en el Sur Global: la investigación se hizo invisible en sus derechos, al mismo tiempo que 
se ingresan en una dinámica de aparente autonomía, responsables por su éxito y fracaso. Por otra parte, las empresas de aplicaciones que se plantean detrás de una narrativa de neutralidad tecnológica y globalización homogeneizadora. El tema principal es reflexionar como la permanente expropiación de los derechos del otro y el discurso del individualismo meritocrático, que acompañan a la dialéctica del centro y de la periferia global, son características fundamentales de la creación del propio capitalismo, de la relación entre colonizadores y colonizados.

PALABRAS CLAVE: Repartidores. Capitalismo global. Colonialidad. Compartiendo economía. Trabajo precario. 